\title{
Experimental and Computational Analysis of Machining Processes for Light-Weight Aluminium Structures
}

\author{
Weinert, K. ${ }^{(1)}$; Biermann, D. ${ }^{(1)} ;$ Kersting, M. ${ }^{(1)} ;$ Grünert, S. ${ }^{(1)}$ \\ ${ }^{1}$ Institute of Machining Technology (ISF), Technische Universität Dortmund \\ Baroper Str. 301, Dortmund 44227, Germany \\ kersting@isf.de, gruenert@isf.de
}

Keywords: Finite element analysis, milling process, end-cross-section

\begin{abstract}
Different possible reasons for defects have to be considered in machining light-weight aluminum structures. In the machining process, the cutting power affecting the workpiece leads to a thermo-mechanical load that can cause undesirable workpiece deformations and thus shape deviations. Moreover, the microstructure and the machined surface can be influenced, which is detrimental to the later application of the structures. Previously conducted experimental and simulative investigations, estimated the circular milling process to be the most suitable machining operation that provides the best compromise between mechanical and thermal loads compared to drilling operations $[1,2]$.

In this paper the results of machining end-cross-sections of an aluminum profile are presented. The machining was obtained by a milling process, which is demanding, because of the low profile stiffness. For this process it is important to know the effects of machining in view of the shape deviations. By means of a Finite-Element-Analysis the deformations of the profile web can be calculated as well as validated by experiments. Based on these results, the appropriate process parameter values for end machining can be defined.
\end{abstract}

\section{Introduction}

The machining of light-weight aluminum profiles raises different problems due to the small wall thickness. The process forces subjecting the workpiece can cause discrepancies in tolerances or even damage. This can lead to a reduction of functional capability and, therefore, a failure. Moreover, the heat, generated within the dry machining process due to the friction and the chips, can cause local displacements.

With the help of advanced workpiece clamping devices, some situations of workpiece damage can be well avoided. However, in most cases the process design has to be optimized.

\section{Experimental Setup}

In order to produce light-weight metallic structures, especially the machining of the section ends requires certain attention. The machining of these profile end-cross-sections is necessary for different subsequent production steps, for example a welding process. In this case not only the exact profile length is important, but also the shape of the machined profile end-cross-section.

The main goals of these investigations are the analysis and the optimization of the process design concerning the applied cutting data. Therefore, the best solution for short major processing time and minimum workpiece deflections has to be determined. Particularly, the plastic yield of the workpiece can cause problems if subsequent processes are to perform. The investigated aluminum alloy was AW 6060, a very ductile workpiece material and therefore very susceptible to deformation due to the process forces.

In order to create structures consisting of profiles with different cross section shapes, a machining operation is necessary to create small welding seams for following welding processes (Fig. 1). As a first example for developing an appropriate part design a rectangular hollow profile was machined 
by a milling process to create a concave end-cross-section. This contour can be used for a $\mathrm{T}$ junction of rectangular and circular structures.

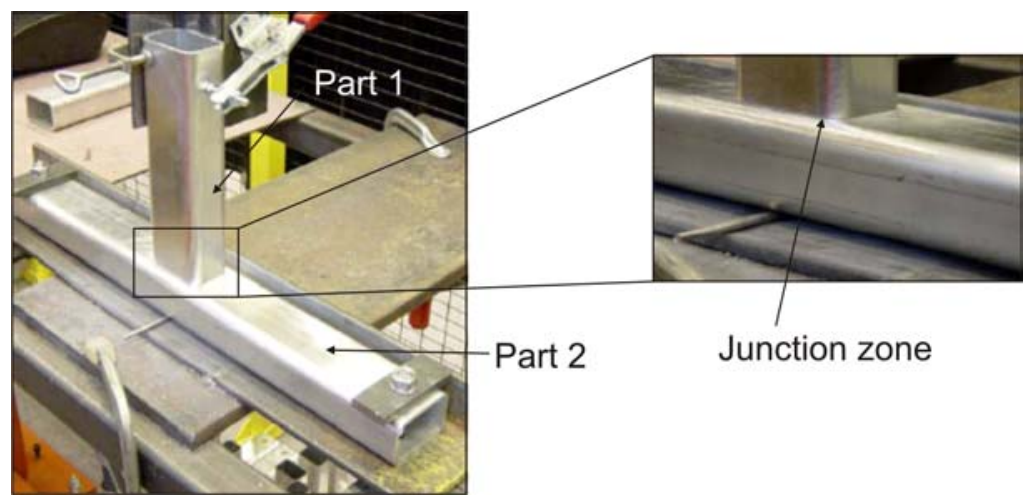

Figure 1: Example for a T-junction with a rectangular profile

At the first step, experimental investigations have been conducted. Therefore, a hollow aluminum profile has been fixed on a three axis machining center, as shown in Fig. 2.

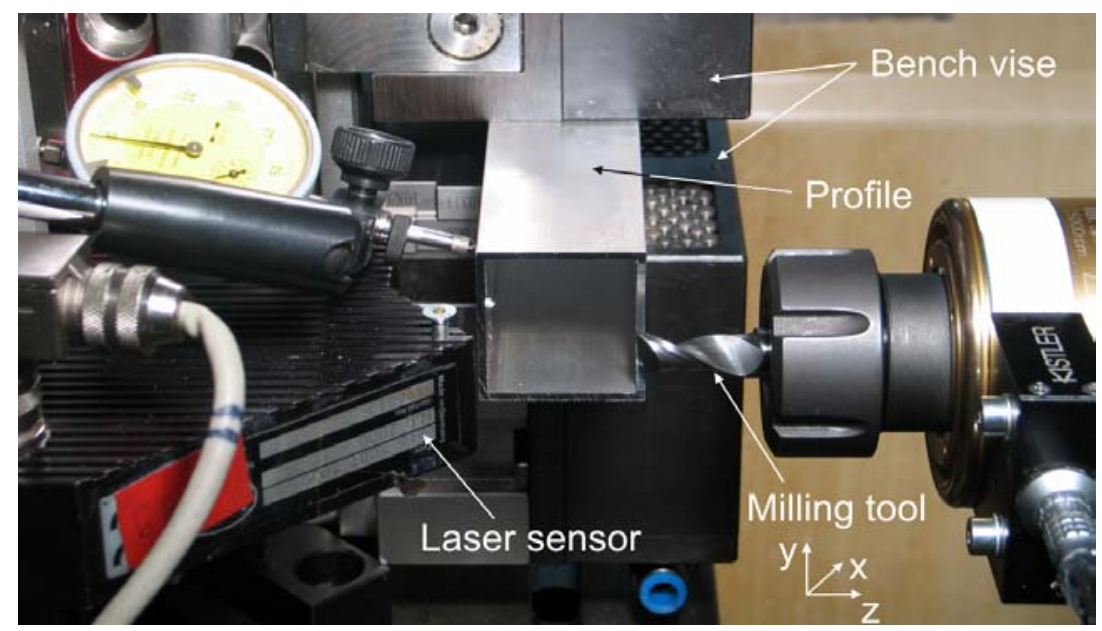

Figure 2: Experimental set up

The profile was fixed on both sides by a conventional bench vise. The hollow aluminum profile had a cross section of $40 \times 40 \times 2 \mathrm{~mm}$ and in one flange of the profile, a circle segment with diameter $\mathrm{D}=40 \mathrm{~mm}$ was machined. The end-cross-sections were deburred for process preparation. The machining operation was performed in up-milling. The offset of the radius to the end-cross-section was $12.3 \mathrm{~mm}$. The used tool was a single tooth milling cutter with diameter $\mathrm{D}=12 \mathrm{~mm}$ and a rake angle of $30^{\circ}$. It was made of fine grain cemented carbide and the cutting edge design is specialized for the machining of aluminum. The machining parameters were varied between feed rate $0.2 \mathrm{~mm}$ and $0.8 \mathrm{~mm}$ and the cutting speed between $200 \mathrm{~m} / \mathrm{min}$ and $800 \mathrm{~m} / \mathrm{min}$.

During the experiments', the deformation in Z-direction of the machined flange was monitored with the help of a laser tracker system. A schematic drawing of the experimental and measuring set up is shown in Fig. 3. Therefore, a small hole was drilled in the middle of the undersurface of the profile. The distance between hole and profile edge was $12 \mathrm{~mm}$. A small laser beam aimed through that hole under the upper surface which was to be machined. The reflected beam was detected by a sensor at a fixed angle. When the machined flange moves or bends due to the process forces the reflection angle changes. This change was measured and the current distance between laser source and upper profile flange can be calculated. Due to the rake angle of the used milling cutter, a movement of the flange in Z-direction is always to be expected. Additionally, a small nozzle for 
compressed air was positioned in front of the profile to ensure that no chips were in between the laser and the detector.

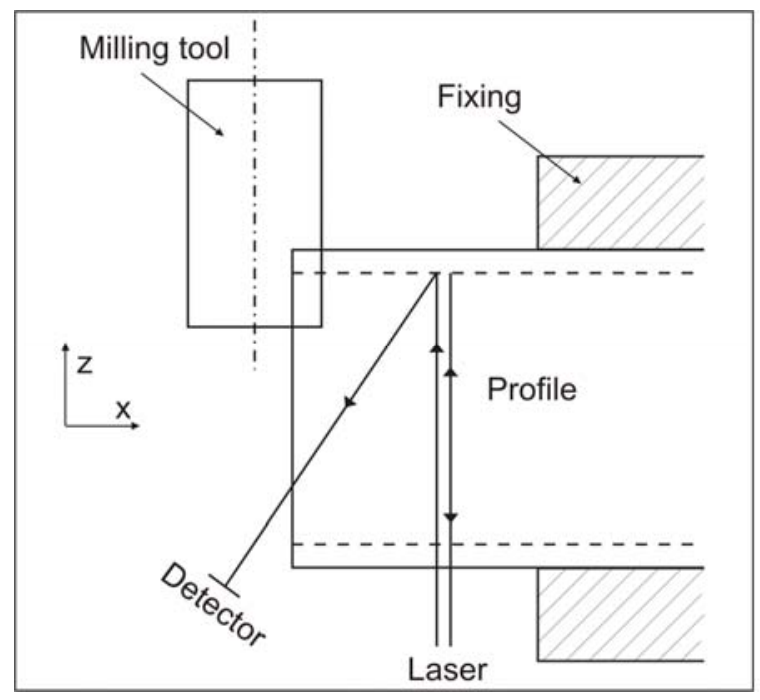

Figure 3: Measurement set up for the detection of the deformation in Z-direction

Furthermore, the mechanical load e.g. the feed force and the cutting torque of the tool is recorded during the process with the help of a dynamometer. In such a way the correlation between mechanical loads and deflected web can be determined. However the stress situation in the machined section can not analytically calculate. With the help of FEA the stress situation can be calculate but therefore the mechanical loads are necessary as input parameter. The feed force and drilling torque was applied on the workpiece (see paragraph FEA of machining end-cross-sections) and the measured deviations of the web during the process were used for validation of the simulation results. Moreover, the measured deviations show which process parameter values are more suitable for the end-cross-section machining of this aluminum alloy. The measured mechanical loads for a certain process parameter set are presented in Fig. 4 and Fig. 5.

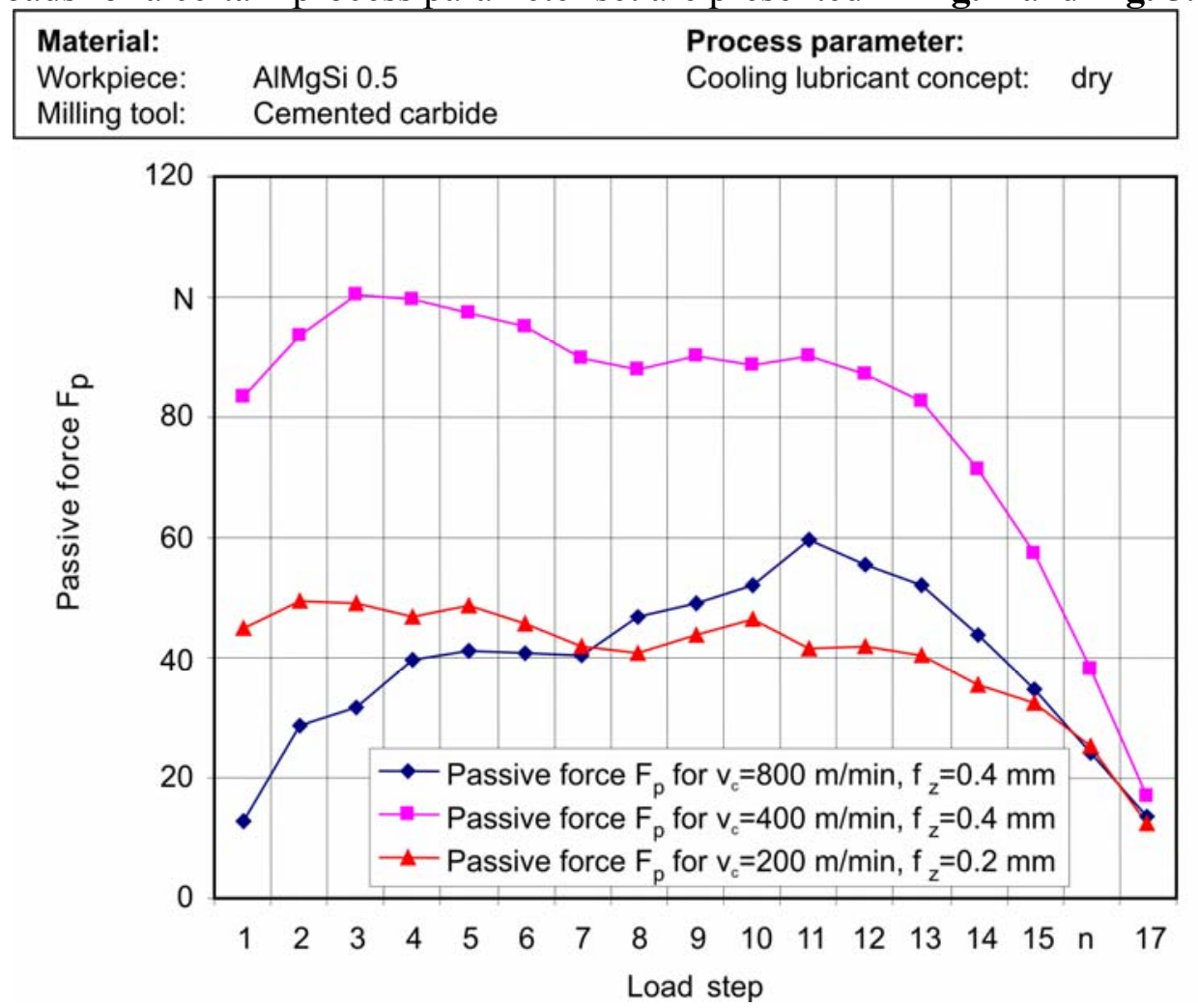

Figure 4: Illustration of passive forces due to varying process parameters 


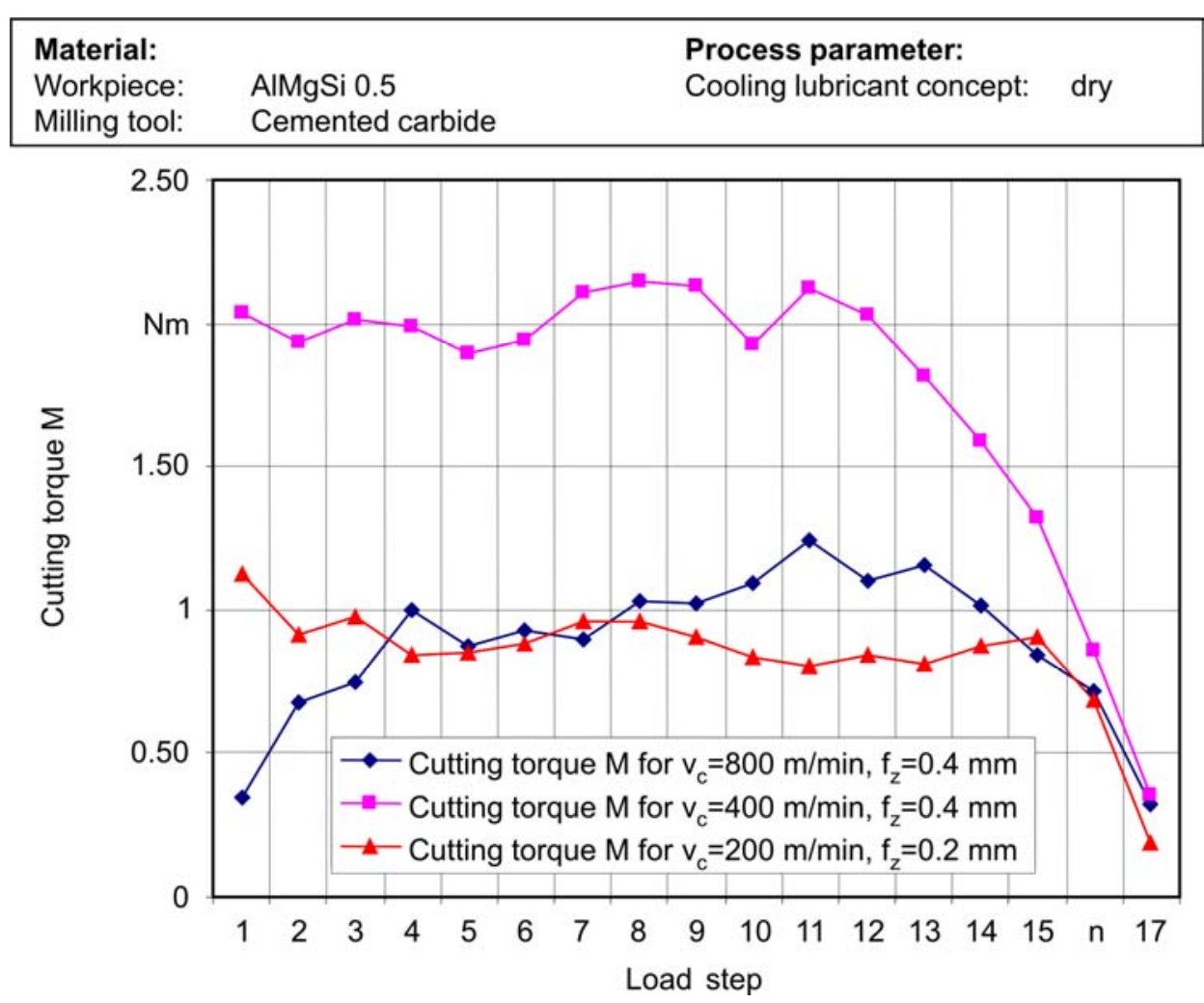

Figure 5: Illustration of cutting torque due to varying process parameters

It is obvious that at a cutting speed of $\mathrm{vc}=400 \mathrm{~m} / \mathrm{min}$ and feed rate of $\mathrm{f}=0.4 \mathrm{~mm} / \mathrm{rev}$ the highest mechanical load was measured. At a higher cutting speed combined with the same feed rate this load is lower. This can be attributed to a decrease in thermal stiffness of the material caused by a higher cutting power in the process accordingly to the equation:

$$
Q_{w}=A \cdot v_{c} .
$$

$Q_{w}=$ Material Removal Rate; $A=$ Cross Section of Undeformed Chip; $v_{c}=$ Cutting Velocity

Due to the high process forces the profile was relocated during the machining operation. This movement caused a deviation to the preprocess coordinates. The clamping situations pre- and postprocess were observed by a test gauge. The amounts of deviation are listed in table 1.

Table 1: Measured profile deviation pre- and post-process

\begin{tabular}{|l|l|l|l|}
\hline & $\mathrm{v}_{\mathrm{c}}=200 \mathrm{~m} / \mathrm{min}$ & $\mathrm{v}_{\mathrm{c}}=400 \mathrm{~m} / \mathrm{min}$ & $\mathrm{v}_{\mathrm{c}}=800 \mathrm{~m} / \mathrm{min}$ \\
\hline $\mathrm{f}_{\mathrm{z}}=0.1 \mathrm{~mm}$ & $0 \mathrm{~mm}$ & $0.002 \mathrm{~mm}$ & $0.005 \mathrm{~mm}$ \\
\hline $\mathrm{f}_{\mathrm{z}}=0.2 \mathrm{~mm}$ & $0 \mathrm{~mm}$ & $0.005 \mathrm{~mm}$ & $0.005 \mathrm{~mm}$ \\
\hline $\mathrm{f}_{\mathrm{z}}=0.4 \mathrm{~mm}$ & $0.02 \mathrm{~mm}$ & $0.02 \mathrm{~mm}$ & $0.05 \mathrm{~mm}$ \\
\hline
\end{tabular}

\section{Finite-Element-Analysis of machining end-cross-sections}

After the experiments, an analysis of the forces and the cutting torque was performed. Especially these data are important for the definition of loads within the FE-modeling. The simulation model for circular milling previously developed at the Department of Machining Technology (ISF) was applied for the simulation of machining process at section ends [3]. In comparison to the circular milling, the end-cross-section machining is a conventional milling operation without movement in Z-direction.

When analyzing the data 17 peaks were observed in the datasheet. For each revolution the major cutting edge of the tool gets into a new engagement and therefore, a peak is observed at the cutting torque and the feed force. These 17 peaks are the reason for discretization of the modeled material 
to be machined within 17 substeps. Within the process material was removed gradually from the model to simulate the chip removal. After each tool revolution one-seventeenth of the material to be machined was detached therefore the model has to be prepared in order to remove the material in the appropriate order. The area which will be machined was modeled as a certain volume. As in former analyzes already proved, the approach of discretisizing is a reasonable way to describe the tool movement along the machined workpiece surface [3].

The simulation of the entire process is only performed without investigating the chip building. The chip building itself is of a high complexity and, therefore, a high amount of calculation time is required $[4,5]$. In order to develop a productive and economic method for prediction of in-process conditions or limitation of functions, only the machined area of the profile should be observed.

To represent the tool and its engagement condition in the workpiece material, an exact measurement of the shape of the used tool was conducted. This data was used to model an exact image of the tool in the FEA environment. During the modeling process different challenges occur due to the complex shape of the single tooth milling cutter. Thus, several idealizations were necessary. On the one hand, the modeling became easier and on the other hand, simpler structures consume less elements and therefore less calculation time.

The major simplification concerns the engagement situation of the tool during the operation. The used tool has a rank angle of $30^{\circ}$. Due to that angle, the line of contact representing the major cutting edge has the shape of a helix. This is difficult to model into the workpiece. Therefore, the major cutting edge was modelled as a straight inclined line (Fig. 6). Due to that supposition the meshing process became easier, too.

The tool material consisting of cemented carbide is very stiff in comparison to the ductile aluminum and thus is assumed as linear elastic material model. The workpiece material is represented as an elastic plastic material depending on the temperature. Therefore an isotropic plasticity was assumed. The Young's modulus was measured of subproject A3 with $\mathrm{E}=63 \mathrm{GPa}$ and a yield point with $\mathrm{R}_{\mathrm{p} 0.2}=74 \mathrm{MPa}$. For the FEA-model the 3-D 8-node structural solid element type SOLID185 implemented in the FE-code ANSYS was used. This element type is a trilinear element, but a linearized shape function is sufficient for structural analyzes with a reduced number of nodes compared with quadratic elements.

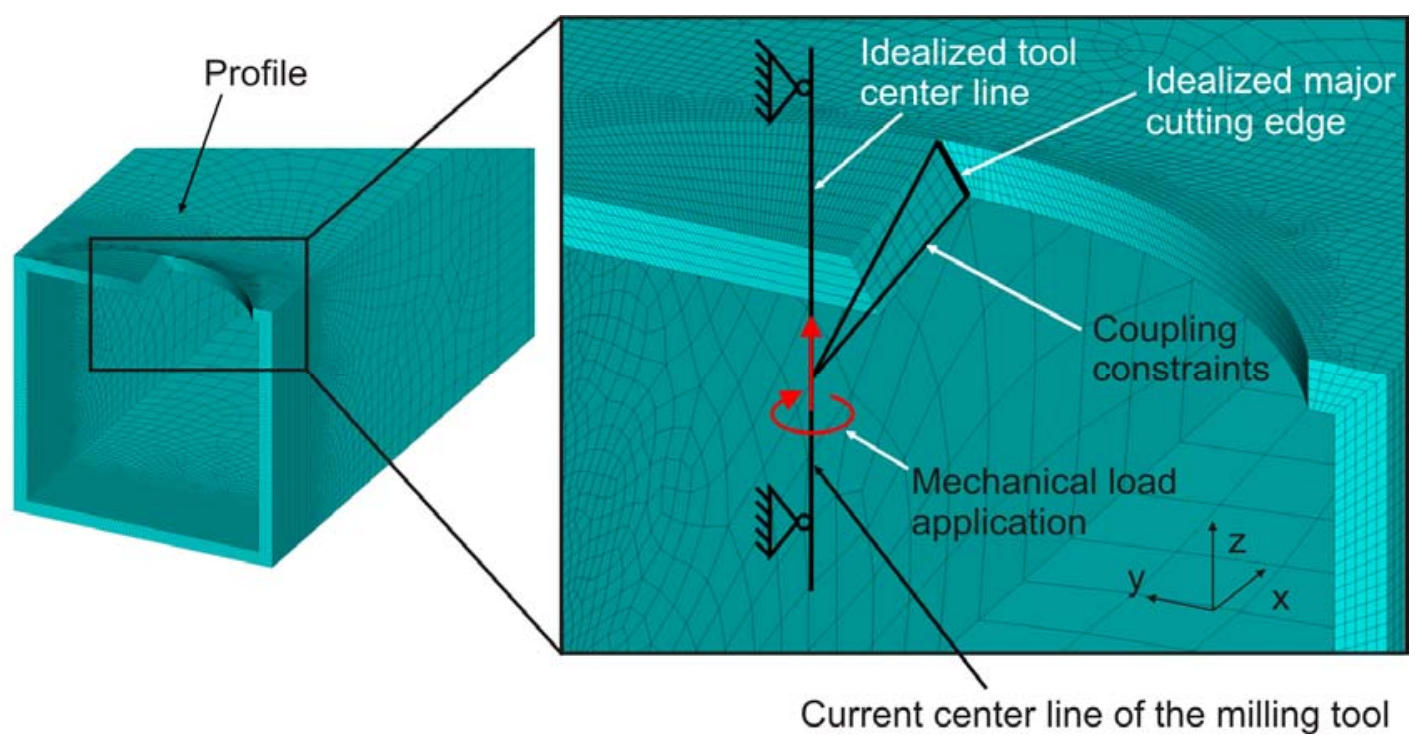

Figure 6: FE-model for end-cross-section machining

The load application was implemented by joint nodes on the supposed tool and the machined area. Therefore, on the virtual tool centre line, a master node was selected and coupled with nodes on the major cutting line in the machined area. On the master node the mechanical load at each load step 
was applied and transferred to the coupled nodes. In the virtual process the tool center line as well as the master node changes along the cut edge due to the movement of the tool in the XY-plane.

The displacement in Z-direction can be compared between calculated and measured values. Fig. 7 and Fig. 8 show that the calculated deformations are lower than the measured ones. Also, it could be observed that the qualitative accordance is good and the difference between the two values is nearly constant. This leads to the conclusion that the approach provides a promising procedure to the experiments, but some improvements are still conceivable. The simulation was conducted for different cutting data (Table 2).

Table 2: Selected process parameter values for the FE-simulation

\begin{tabular}{|l|l|l|}
\hline & Cutting speed $\mathbf{v}_{\mathbf{c}}$ & Feed rate $\mathbf{f}_{\mathbf{z}}$ \\
\hline Parameter value combination 1 & $200 \mathrm{~m} / \mathrm{min}$ & $0.2 \mathrm{~mm}$ \\
\hline Parameter value combination 2 & $400 \mathrm{~m} / \mathrm{min}$ & $0.4 \mathrm{~mm}$ \\
\hline
\end{tabular}

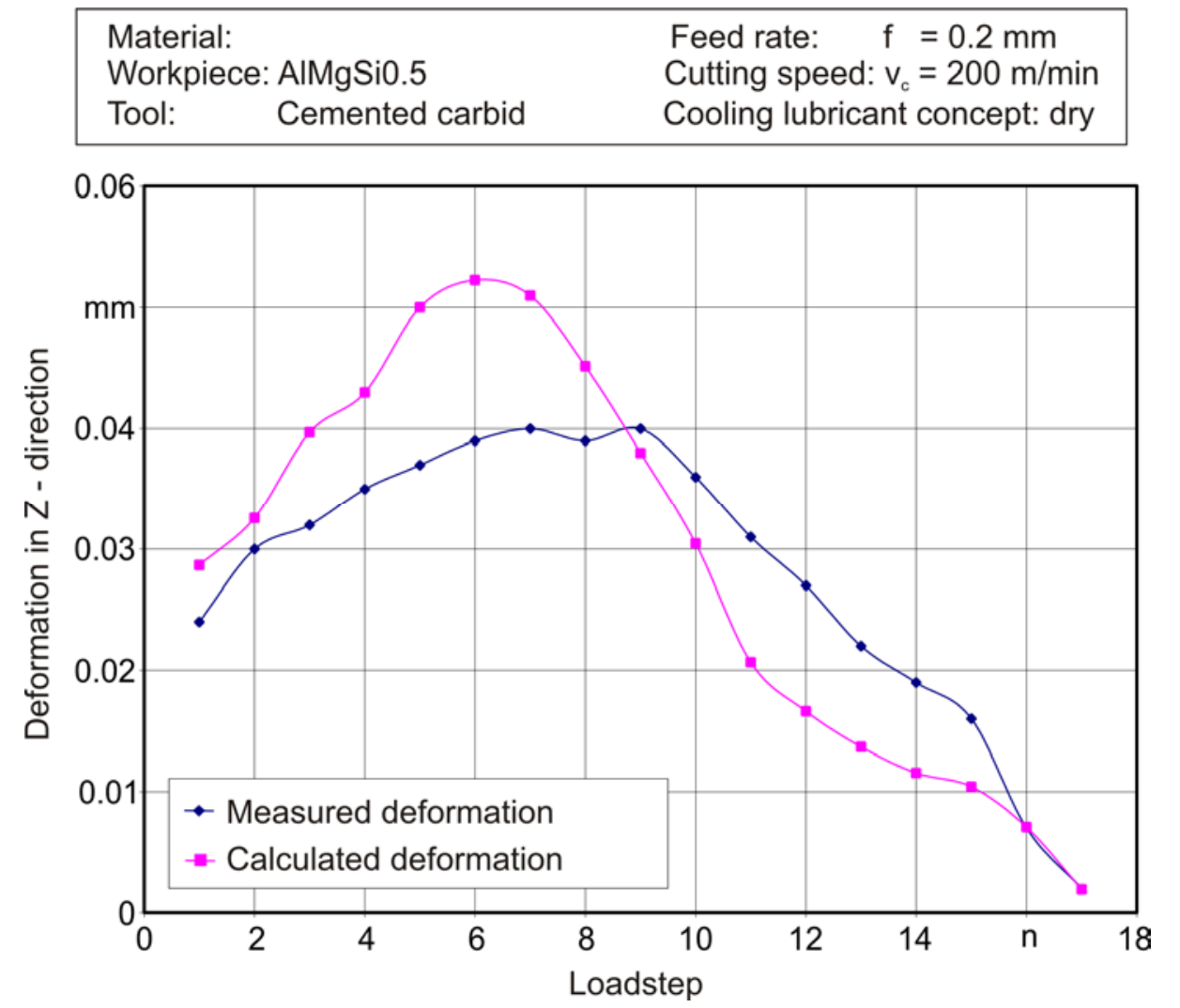

Figure 7: Comparison calculated and measured deformation for the first parameter value combination 


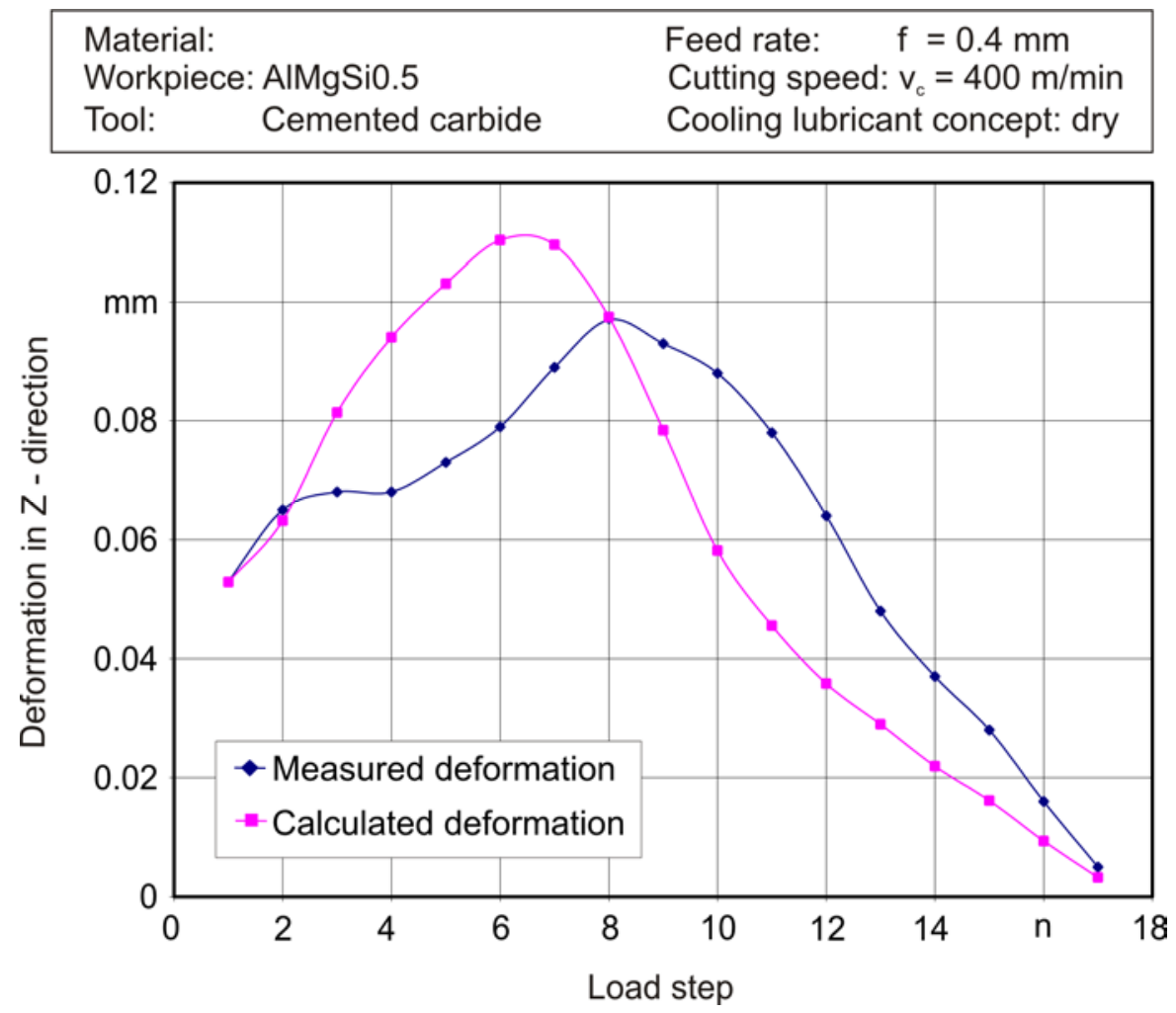

Figure 8: Comparison calculated and measured deformation for the second parameter value combination

The good accordance between measured and calculated displacements offers an interpretation of the stress values calculated by the FEA software. The stress values depend on the deformations therefore high deformations lead to higher stress values. The stress is shown as von Mises equivalent stresses (Fig. 9), this is a commonly used hypothesis for aluminum [6]. It is obvious that the stresses are limited on a small area around the contact zone. There is no additional influence on the entire profile. At the load steps 7 and 8 the stress values are the highest accordingly to the highest deformations. Furthermore the stress values are not that high that plastic deformations takes place.

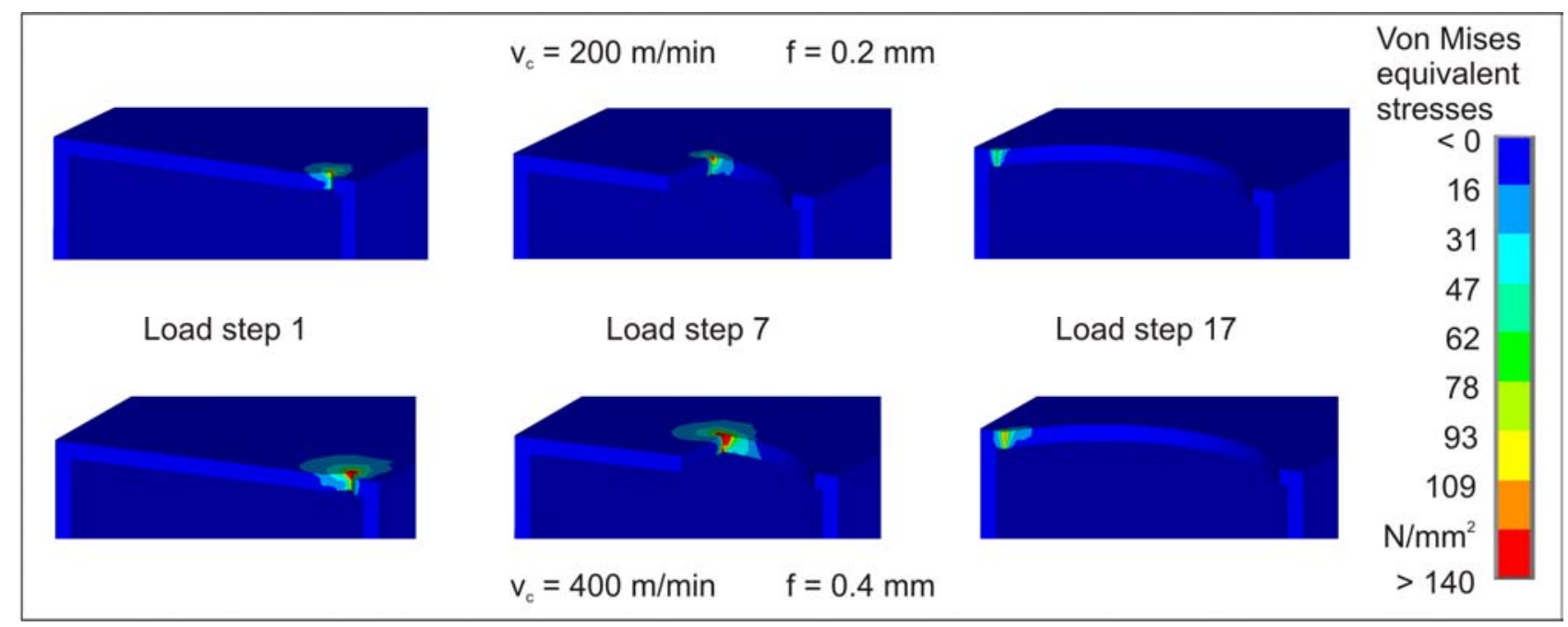

Figure 9: Von Mises equivalent stresses for selected load steps and parameter values 


\section{Summary and Conclusion}

The investigations of machining end-cross-sections of aluminum hollow profiles with a low stiffness show the complexity of this process. The measured deformations in axial direction of the tool center line show varying results. Contrary to the expectance the mechanical load at low cutting speed and feed rate is equal or higher than on higher parameter values. This phenomenon can be explained by decreasing stiffness of the material in consequence of generated heat at higher cutting speed.

Following on from the investigations of the machining process, the simulation is to be integrated into a virtual process chain for small-batch manufacturing of unreinforced and reinforced profiles with different, including multi-cell cross sections. Especially the reinforced extruded profiles contain residual stresses, because of the different thermal expansion of matrix and reinforcement elements during the cooling phase after extrude moulding. The residual stresses may have negative effects on the manufacturing accuracy when cutting the reinforcement during the machining process. Because of this, it is necessary to consider these internal stresses of the profile as an initial condition for the machining simulation. This is necessary for bore holes, especially when they are located close to each other, and for section ends, because of the shape accuracy influencing the following welding process.

\section{Acknowledgement}

This paper is based on investigations of the Collaborative Research Center SFB/TR10 which is kindly supported by the German Research Foundation (DFG).

\section{References}

[1] Weinert, K.; Kersting, M.; Schulte, M.; Peters, C.: Finite Element Analysis of Thermal Stresses During the Drilling Process of Thin-Walled Profiles. Production Engineering - Research and Development, Annals of the German Academic Society for Production Engineering, XII (2005) 1, ISBN 3-9807670-6-x, pp. 101-104

[2] Weinert, K.; Grünert, S.; Hammer, N.; Kersting, M.: Analysis of Circular Milling Processes for Thin-Walled Space-Frame-Structures Applying FEA-Simulation. Production Engineering Research and Development, Annals of the German Academic Society for Production Engineering, XII (2005) 1, ISBN 3-9807670-6-X, pp. 99-102

[3] Weinert, K.; Grünert, S.; Kersting, M.: Analysis of Cutting Technologies for Lightweight Frame Components. In: Flexible Manufacture of Lightweight Frame Structures, Kleiner, M. et al. (eds.), TTP Trans Tech Publications Ltd, Switzerland, Vol. 10 of Advanced Materials Research, ISBN 0-87849-403-0, pp. 121-132, 2006

[4] Risse, K.: Einflüsse von Werkzeugdurchmesser und Schneidkantenverrundung beim Bohren mit Wendelbohrern in Stahl. Dissertation, RWTH Aachen, 2006

[5] Söhner, J.: Beitrag zur Simulation zerspanungstechnologischer Vorgänge mit Hilfe der FiniteElement-Methode. Dissertation, TU Karlsruhe, 2003

[6] Schnell, W.; Gross, D.; Hauger, W.: Technische Mechanik. Band 2 Elastostatik. SpringerVerlag Berlin, ISBN 3-540-64147-5, 1998 